Publicación semestral. ISSN 2215-4906

Volumen 80 - Número 2

Enero - Junio 2021

\title{
Algunas aproximaciones a la relación entre el arte pictórico y la práctica educativa: descripción de un sentimiento pedagógico
}

Some Approaches to the Relationship between Pictorial Art and Educational Practice: Description of a Pedagogical Feeling

Mauricio Prada Arévalo

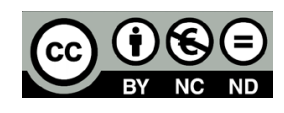

Esta obra está bajo una licencia Creative Commons Reconocimiento-No comercial-Sin Obra Derivada 


\title{
Algunas aproximaciones a la relación entre el arte pictórico y la práctica educativa: descripción de un sentimiento pedagógico
}

\author{
Some Approaches to the Relationship between Pictorial Art \\ and Educational Practice: Description of a Pedagogical Feeling \\ Mauricio Prada Arévalo ${ }^{1}$ \\ Corporación Universitaria Minuto de Dios-Uniminuto \\ Colombia
}

Recibido: 20 de agosto de 2020 Aprobado: 5 de noviembre de 2020

\begin{abstract}
Resumen
El presente artículo indaga a partir de algunos referentes teóricos, experiencias pedagógicas y reflexiones diversas, sobre la relación existente entre el arte pictórico y la práctica educativa en la formación y la cultura humanas. Esta conexión se ha evidenciado desde los orígenes de la civilización y ha llegado, después de numerosas transformaciones, al escenario educativo contemporáneo, el aula de clases y el currículo. En ella han sido relevantes muchos aspectos de índole histórica, cultural y teórica. Lejos de ser un tema superado, el vínculo que mantiene el arte pictórico con la práctica pedagógica es un campo en donde germinan consideraciones filosóficas y experiencias didácticas que pueden colaborar en la necesaria transformación de la educación en sus distintos niveles y ámbitos. Aquí se describirán algunos de esos elementos y experiencias con sus diversas consideraciones académicas, usos didácticos y logros pedagógicos.
\end{abstract}

Palabras clave: pintura; cultura; educación artística; filosofía; conocimiento

1 Docente Investigador, Unidad de Educación en la Corporación Universitaria Minuto de Dios, Sede San Camilo. Magíster en Enseñanza de la Educación Superior por la Universidad El Bosque, Colombia. ORCID: 0000-0002-6056-089X. Correo electrónico: mauricio.prada@uniminuto.edu 
Algunas aproximaciones a la relación entre el arte pictórico

Artículo y la práctica educativa: descripción de un sentimiento pedagógico

\begin{abstract}
The present article explores, from some theoretical referents, pedagogical experiences and diverse reflections, on the existing relation between the pictorial art and the educative practice in the formation and human culture. This connection has been evident since the origins of civilization and has come, after numerous transformations, to the contemporary educational scene, the classroom and the curriculum. In those topics, many aspects of historical, cultural and theoretical nature have been relevant. Far from being a surpassed subject, the bond that maintains the pictorial art with the pedagogical practice is a field where germinate philosophical considerations and related experiences that can collaborate in the necessary transformation of the education in their levels and scopes. Here some of those elements and experiences and their diverse academic considerations, didactic uses and pedagogical achievements will be described.
\end{abstract}

Keywords: painting; culture; art education; philosophy; knowledge 


\section{Introducción}

Desde tiempo inmemorial el ser humano ha utilizado imágenes, símbolos y dibujos para alcanzar diversos fines. Algunos de ellos han representado necesidades y expectativas propias de sus vivencias personales, momentos históricos y contextos culturales. Si se analizaran con rigor estas finalidades y el modo en que se alcanzaron se advertiría, con especial claridad, que una buena parte de ellas hicieron de la representación pictórica una manera efectiva de transmitir y enseñar ciertos contenidos. El arte pictórico, desde sus más primitivas aplicaciones, ha tenido una dimensión pedagógica que aún hoy no ha sido descrita y analizada en su totalidad.

La iconografía religiosa, la creación literaria, las costumbres ancestrales y las prácticas educativas de las distintas etapas históricas han sido escenarios válidos en donde el arte ha desarrollado elementos imprescindibles para el progreso humano. En Egipto y algunas civilizaciones mesopotámicas, el arte pictórico ocupó diversos ámbitos de aprendizaje y desarrollo como la arquitectura, la decoración de monumentos funerarios, la elaboración de cerámicas y la escultura. En Grecia y Roma se divulgó en la educación, la literatura y la filosofía. En la edad media europea fue el vehículo de expresión de la evangelización cristiana. En el Renacimiento constituyó una esfera de la cultura cuya tarea alentó el proceso de la fundamentación estética. En la Modernidad desempeñó un papel determinante en la configuración política de la civilización contemporánea.

Al igual que en el desarrollo histórico de la cultura humana, el arte pictórico ha encontrado espacios en la escuela y en ella ha experimentado una percepción y una valoración diferentes de los demás contextos. Dentro de la escuela ha sido concebido como una materia más, con frecuencia de carácter complementario, y poco se ha considerado su presencia y su articulación como fines o medios para el trabajo académico. Al decir de Read, (2013), "la mayoría de los sistemas pedagógicos parecen concebidos con el deliberado fin de anular la sensibilidad estética del niño. Con raras excepciones, la instrucción pública se aplica hoy, en todo el mundo, a inculcar el conocimiento intelectual" (p. 127), lo cual quiere decir que una buena parte del relato educativo contemporáneo privilegia el discurso teórico sobre otras formas y objetos de conocimiento como la belleza y la imagen.

En el siglo XX, el arte pictórico fue un recurso regularmente aplicado en la formación escolar de la infancia y la adolescencia; pero en niveles superiores de educación fue marginado como método, fin y contenido de procesos de enseñanza y aprendizaje. Las 
Algunas aproximaciones a la relación entre el arte pictórico

Artículo

y la práctica educativa: descripción de un sentimiento pedagógico

dimensiones del arte pictórico como recurso y objeto de conocimiento no se encuentran del todo exploradas y aplicadas en los contextos escolares, lo que hace, de alguna manera, pobres a las prácticas pedagógicas de hoy. A pesar de dicha condición se presentan, sin embargo, experiencias significativas que se han venido multiplicando en los últimos años, proporcionando a la escuela una oportunidad de mejora y de cambio.

En Colombia, particularmente, el empleo del arte pictórico es notorio sólo en espacios restringidos y considerados por las mayorías como "culturales"; apreciación que desconoce la categoría de cultura que reviste el aula escolar por el sólo hecho de ser el ámbito en donde se educa a las nuevas generaciones. Por mucho tiempo se consideró como cultura un tipo de difusión de creaciones artísticas que en nada tocaban el espíritu y la sensibilidad de las masas, sin embargo, todo lo que la escuela y la universidad hacen desde sus programas, orientaciones políticas y concepciones filosóficas es cultura.

\section{Situación problemática}

Lo anterior llama la atención sobre la condición problemática del presente artículo y los interrogantes que la componen: ¿cuáles son las principales concepciones del arte pictórico?, ¿cuál podría ser hoy el papel del arte pictórico en la formación de jóvenes y ciudadanos en la escuela y fuera de ella? ¿en qué espacios se encuentra el arte pictórico como expresión del conocimiento, de las emociones y los sentires colectivos?, cuestiones que jalonan la exposición de los siguientes temas, sirven de apoyo a la reflexión aquí contenida y suponen una pregunta problematizadora más general: ¿cuál es el aporte teórico, su sentido y alcance, desde las diversas fuentes bibliográficas, que hoy se encuentra sobre la relación entre el arte pictórico y la práctica educativa? Interrogación, además, que sintetiza la perspectiva analítica del texto y origina el planteamiento del esquema metodológico y el uso de algunos conceptos que conforman la visión teórica del escrito.

\section{Algunos fundamentos}

A pesar de constituir un trabajo de reflexión y perspectiva interpretativa, los presupuestos tienen que ver con el papel desempeñado por el arte pictórico en diversos contextos de aprendizaje tales como la lectura poética, la visita al museo, las imágenes en las calles, el aula hospitalaria, el aula escolar y otros apenas insinuados. En dichos ámbitos se piensa que el arte pictórico es un recurso que contribuye a la formación de los sujetos y a la percepción de diferentes realidades que pueden favorecer nuevas perspectivas 
de conocimiento y construcción del saber. El empleo pedagógico del arte pictórico ayuda en la comprensión de fenómenos para los cuales el discurso tradicional de la escuela y la teoría pueden resultar insuficientes. Las imágenes pictóricas, aunque no alcanzan a traducirse en lenguaje escrito, comunican aspectos constitutivos de la realidad que logran ser aprendidos. En el plano teórico, esta perspectiva está fundamentada en la visión pedagógica del arte, cuyos logros específicos señalan que la imagen, sea ésta la pintura, el dibujo, el logo, la fotografía u otras, tiene gran poder de comunicación e influye positivamente en dinámicas relacionadas con la práctica educativa no sólo dentro del aula sino también fuera de ella.

El uso apropiado de la imagen produce en los estudiantes mensajes de fácil recordación frente a aquellos que son emitidos verbalmente: la fotografía, el cine, la televisión y el computador, entre otros, utilizan la imagen como medio para trasmitir mensajes, que aplicados bajo estrategias pedagógicas apropiadas en el aula, posibilitan la enseñanza y el aprendizaje de una manera más agradable y significativa (Bedoya, 2009, p, 198).

Las consideraciones pedagógicas, así como la anterior, y también las teorías clásicas de la estética como las propuestas por Immanuel Kant, Friedrich Hegel, y Herbert Read, señalan siempre este potencial del arte en términos de mostrar acontecimientos, ideas y fenómenos, al espíritu humano. El hecho de que tanto la pedagogía artística como la estética confluyan en este convencimiento es un punto teórico de partida en la descripción de estas temáticas y también el soporte de algunos razonamientos presentes en el escrito.

\section{Estrategia metodológica}

A partir de la pregunta-problema y de los supuestos que constituyen sus alcances y sentidos, la revisión documental se orientó bajo el canon de la matriz de búsqueda sistemática: se realizó una indagación en bases de datos especializadas con criterios de inclusión de artículos y fuentes primarias que tuvieran en cuenta la pertinencia y que respondieran a las preguntas que constituían el interrogante principal. Los textos seleccionados recopilaban consideraciones teóricas sobre el papel del arte en la formación académica y se caracterizaban por su minuciosidad en la exposición. Algunos criterios anexos a la pertinencia temática y al cuidado en el desarrollo del tema estaban dados por la alusión a pinturas de los grandes maestros, la descripción de métodos de comprensión del arte, como la iconología, la semántica y los análisis pictóricos con cierta vocación metafísica, en los cuales no se reducían sus características a simples datos empíricos.

ESCENA. Revista de las artes, 2021, Vol. 80, Núm. 2 (enero-junio), pp.56-80 
Algunas aproximaciones a la relación entre el arte pictórico

Artículo

y la práctica educativa: descripción de un sentimiento pedagógico

En este sentido, los aportes de los maestros Carlos Ramírez Aissa y Francisco Gil Tovar, resultaron determinantes por cuanto sus textos fueron ciertamente pioneros en el acercamiento al arte en el ámbito universitario en Colombia. Igualmente, y como se señalaba, las aportaciones de Kant, Hegel y Read, que todavía enfatizan aspectos relevantes del arte vinculados con los sentidos y el pensamiento. Después de la selección de los artículos y textos se procedió a un análisis de tipo semántico, en el cual los principales fragmentos se recopilaron en orden a conformar un corpus que sirviera como insumo principal de la reflexión. La metodología tuvo que ver con la separación de fragmentos de acuerdo con sus temas (relación arte-educación, importancia del arte pictórico, métodos y campos de aplicación). Al final del proceso se hizo la contrastación entre las ideas principales y las aportaciones de la pedagogía artística, de modo que se configurara una visión integral de las respuestas a la pregunta-problema y a las cuestiones que la sostenían. Así pues, en el cumplimiento de la dinámica metodológica, se obtuvieron algunos puntos significativos que se sintetizaron en el texto.

\section{Arte pictórico y obra de arte: consideraciones sobre su naturaleza}

Determinar qué es y qué se ha entendido por arte pictórico es una tarea difícil: el arte pictórico es un fenómeno que abarca épocas históricas, lugares y culturas diferentes. Desde la tradición teórica se le ha reducido al acontecimiento denominado pintura, pero en su acepción más común hace referencia a todas las maneras de representar gráficamente la realidad. Carrillo, (2017) afirma al respecto:

La historia de la pintura ha tenido un desarrollo cronológico y estilístico paralelo en gran medida al resto de las artes plásticas, si bien con diversas particularidades en el tiempo y el espacio debidas a numerosos factores, desde los derivados de las diversas técnicas y materiales empleados en su confección hasta factores socio-culturales y estéticos, ya que cada pueblo y cada cultura ha desarrollado a lo largo del tiempo distintos conceptos de plasmar la imagen que recibe del mundo circundante. La pintura es el arte y técnica de crear imágenes a través de la aplicación de pigmentos de color sobre una superficie, sea papel, tela, madera, pared, etc. (p. 1).

Lo cual señala que a pesar de la diversidad de escenarios para definir el arte pictórico, técnicamente, aquél es un proceso para crear imágenes a partir de mecanismos y recursos físicos, y también los productos de este proceso, es decir, las imágenes mismas. Así que el arte pictórico es a la vez resultado de un proceso y proceso de ese mismo resultado.

ESCENA. Revista de las artes, 2021, Vol. 80, Núm. 2 (enero-junio), pp. 56-80 
Se considera a la obra de arte como el producto real y material del arte pictórico, aunque hay obras de arte asociadas a otros procesos creativos provenientes de la literatura, la escultura, la arquitectura, el cine y demás expresiones artísticas. La obra de arte está entendida como creación novedosa. Es una manera de hacer visible algo que no lo está. Es una expresión del genio y del talento que busca comunicar algo y que siempre se renueva, manteniendo su naturaleza dinámica y abierta. La concepción más común de la obra de arte y del arte pictórico acentúa el carácter de perfección que de suyo tienen. "Podemos considerar el arte como un lenguaje plasmado en el objeto de arte. Éste presenta un proceso de elaboración de un objeto material que de acuerdo con la forma que recibe, expresa y comunica el contenido espiritual de manera objetiva" (Ross, 2004. p. 1).

Desde la óptica de la teoría, conceptualizar la obra de arte es una tarea infinita que presenta distintas consideraciones y dificultades. Para determinar qué es una obra de arte hay que analizar su relevancia en el contexto y algunos otros rasgos especiales:

- A cada época histórica corresponde un imaginario cultural que encarna un concepto, así sea aproximativo, de la obra de arte. Hegel (2002) [1842] señalaba que algunos ídolos de religiones antiguas eran expresiones artísticas del sentir religioso pero difícilmente podrían ser consideradas como obras de arte en su época, el siglo XIX. La cronología es una consideración necesaria para juzgar el verdadero arte: la obra de arte tiene su tiempo.

- La obra de arte es una conquista de la singularidad, es decir, una expresión absoluta de su creador. Sus características son particulares y aunque existan un estilo y un género para ella, sigue siendo un producto individual.

- La obra de arte es una obra humana, ha sido pensada, contemplada y ejecutada por seres humanos. Hoy se diseñan y construyen máquinas que producen objetos, pero difícilmente pueden éstos y aquéllas ser considerados obras de arte. Una buena parte de ambos constituyen elementos para uso doméstico, para servicios especializados y para actividades de consumo.

- La obra de arte expresa siempre algo, dice alguna cosa, y ésta puede ser de naturaleza cultural, política, social, religiosa, económica y demás. No hay obras de arte de la insignificancia o de la nada. Todo objeto artístico comunica un sentir, un pensamiento, o una visión valorativa de la realidad en algunas de sus notas constituyentes. 
Algunas aproximaciones a la relación entre el arte pictórico

Artículo

y la práctica educativa: descripción de un sentimiento pedagógico

Por lo anterior se evidencia que la obra artística es síntesis y expresión de procesos vinculados con la naturaleza íntima del arte pictórico, y ambos comparten sus lugares en el tiempo y en la civilización humana. Las obras de arte en su creación y en su potencial comunicativo son maneras de aprendizaje que a partir de las características descritas se transforman en objetos del ver, del disfrutar y del saber. Sus funciones abarcan diferentes ámbitos de las habilidades humanas y desde la perspectiva estética son diversas; se podría decir que las pinturas de los creadores, tanto reconocidos como inéditos, copan un universo humano y físico infinito.

\section{Ámbitos del arte pictórico asociados a la práctica educativa}

Determinar el conjunto de espacios, usos y ventajas del arte pictórico en relación con las prácticas educativas es un tema relativamente nuevo en el campo de la reflexión pedagógica, y en Colombia apenas se ha insinuado en algunas experiencias de la reflexión académica universitaria. El potencial del arte pictórico en términos de socialización e innovación es significativo, muchos autores así lo sostienen:

Identificamos de esta manera una función contemporánea de las artes básicamente integradora y relacional, que pretende conectar con todos los sustratos de la realidad que compartimos, y no sólo como una manifestación superior del espíritu humano. En definitiva, una función sustentada desde las condiciones necesarias para entender que las producciones culturales no son privilegio de tan sólo unos pocos que producen y reparten la cultura, sino un derecho de todos y cada uno de los existentes (Abad, 2009, p. 17).

A través de las artes, los seres humanos se conocen, se integran y se conectan con sus realidades más próximas. El arte pictórico es un atajo que lleva a las personas tanto a las esferas de las más altas creaciones como a los caminos más cercanos de la experiencia. Este carácter del arte, su ductilidad y su capacidad para comunicar y representar, son las más importantes en el ámbito educativo.

El arte pictórico y la literatura comparten la meta de transmitir un mensaje y comunicar un significado, y por ello apelan a los sentidos y brindan, gratuitamente, algunos contenidos que pueden ser enseñados. En los contextos de hoy, sin embargo, ese potencial educativo se sustrae a la experiencia pedagógica. Con frecuencia se olvida la dimensión estética de las experiencias humanas y la inclinación natural de las personas a sentir y vivir la belleza:

ESCENA. Revista de las artes, 2021, Vol. 80, Núm. 2 (enero-junio), pp. 56-80 
Solamente a través de los sentidos puede tener lugar el aprendizaje. Esto quizá parezca una cosa obvia; sin embargo, sus consecuencias aparentemente, no se tienen en cuenta en nuestro sistema educacional. Es posible que la educación esté simplemente reflejando los cambios que se producen en nuestra sociedad, pues parece que el hombre [ser humano] cada vez confía menos en el contacto real con el ambiente a través de los sentidos. El hombre [ser humano] se está convirtiendo en un observador pasivo de su cultura, antes que en un constructor activo de ella (Lowenfeld y Britain, 1975. p. 51).

Por ello, la ausencia y presencia del arte pictórico en la escuela constituyen fenómenos intermitentes y pendulares, y llaman la atención sobre el proceso de continua automatización del ser humano en el siglo XXI. Dado que la escuela reproduce de alguna manera su entorno y modos culturales, se podría afirmar que la educación que imparte estaría incompleta sin la experiencia estética de los sentidos. En tanto las prácticas educativas se alejen de la belleza del arte pictórico y del arte en general, el ser humano, proporcionalmente, estará más ausente de su vida particular. El encuentro con la obra artística es pedagógico sólo en la medida en que se abandone el concepto y se dé vía libre a los sentidos. Allí reside la fuerza del arte como manifestación del espíritu. "El arte está más próximo al espíritu y su pensamiento que la naturaleza exterior, inerte e inanimada. El espíritu se vuelve a hallar a sí mismo en los productos del arte" (Hegel, 2002, p. 65). Así que, si existe un aprendizaje a través del arte, aquél consiste en un volverse a sí mismo; como una especie de encontrarse en la obra de arte, y esto no sería posible si la obra de arte nada dijese. Por ello, lo que dice el arte supera al conocimiento teórico en tanto es un objeto que encuentra su profunda significación en lo humano. El arte no es sólo un recurso sino un elemento dinamizador de la estructura cognitiva, y en este humano volverse no sólo actúa como un inusitado vínculo entre la naturaleza, la obra de arte y el espectador, sino como un mecanismo de reconocimiento de lo Otro, lo elemental en la naturaleza y el arte, que es lo elemental en la conciencia cognoscente, tal como podría sugerir el poema número 15 de Roberto Juarroz:

Nos quedamos a veces detenidos $\backslash$ en medio de una calle, / de una palabra / o de un beso, / con los ojos inmóviles \ como dos largos vasos de agua solitaria,/ con la vida inmóvil / y las manos quietas entre un gesto y el que hubiera seguido, / como si no estuvieran ya en ninguna parte. / Nuestros recuerdos son entonces de otro, / a quien apenas recordamos. / Es como si prestásemos la vida por un rato, / sin la seguridad de que nos va a ser devuelta / y sin que nadie nos la haya pedido, / 
Algunas aproximaciones a la relación entre el arte pictórico

Artículo

y la práctica educativa: descripción de un sentimiento pedagógico

pero sabiendo que es usada / para algo que nos concierne más que todo. / ¿No será también la muerte un préstamo, / en medio de una calle, / de una palabra / o de un beso? (Juarroz, 1958, p. 38).

La obra de arte y el arte pictórico habitan en los sentidos, en la percepción y en los sentimientos. El volverse hacia lo otro y hacia sí mismo, aprender de ello y evocar ello en nosotros, es asunto de arte y de aprendizaje. Por eso, el uso del arte pictórico y del arte en general, es un espacio para un aprendizaje íntimo y poético. La conciencia y la sensibilidad son los primeros ámbitos en los cuales el arte pictórico puede ser un recurso y un objeto de naturaleza pedagógica. En el poema citado, por ejemplo, la percepción de la naturaleza y del instante reclama de inmediato un ejercicio de introspección y una resignificación: sólo los sentidos le permiten al artista preguntarse sobre sí, sobre sus recuerdos, que son parte de su yo profundo. Por eso el observador y el artista son estudiantes y maestros a la vez. La aprehensión estética es comparable a la aprehensión epistemológica. El conocimiento arranca de la visión y de la percepción: un poco antes del dato se encuentra la belleza y la cualidad. Debido a esto resulta necesario superar el prejuicio en torno al arte pictórico en la práctica educativa, a lo menos en cuanto a sus posibilidades formativas. "La actividad artística, múltiple e integradora, tiene distintas funciones en diversas épocas y grupos pero tal vez la más importante sea la de lograr comunión, producir armonía, dar placer, reflejar conflictos internos, estructurar la realidad y desarrollar la capacidad creadora" (Ross, 2004. p. 2).

Desde la tradición de la pedagogía también puede advertirse esta convicción pero en sentido contrario: desde lo externo hacia lo interno, desde el entorno más próximo, el aula escolar, hasta la conciencia cognoscente: el estudiante. Juan Amós Comenio, por ejemplo, señalaba que "La escuela debe ser un lugar agradable. Por dentro debe ser una sala llena de luz y adornada de pinturas por todas partes, ya sean retratos de varones ilustres, ya mapas, ya representaciones, ya otra clase de símbolos." (Comenio, 2013, p. 96). El primer pedagogo percibía que había una relación directa entre el uso de la imagen y la motivación para aprender. El arte pictórico no es sólo estimulante sino agradable. La imagen está presente como invitación y también como insinuación. En la evocación de los vivientes sobre sus escuelas y tiempos de formación aparecen en sus recuerdos las imágenes; hasta el maestro, en su papel de expositor y motivador, es evocado como estampa visual. Así pues, el recuerdo y la memoria vienen a constituir el segundo gran espacio en que el arte pictórico se consolida como un agente educador.

ESCENA. Revista de las artes, 2021, Vol. 80, Núm. 2 (enero-junio), pp. 56-80 
El arte pictórico es también un modo de conocimiento. En la pintura, o quizás, detrás de ella, hay encerrada y sugerida, una visión interpretativa del mundo. Que esta interpretación sea una simulación o una representación es un acontecimiento fortuito. De cualquier modo, se hace evidente que el espectador de la obra de arte se vuelve cómplice del pintor en la medida en que éste comparte una visión de la realidad que ambos pueden vivenciar.

El objeto de la interpretación no es un hecho físico, sino una representación o lenguaje en el que hay una materia concreta y una verdad universal. Siendo un símbolo, consta de una parte visible y otra invisible, es exterior e interior, concreta y abstracta. Afecta a nuestros sentidos y a nuestro espíritu (Ramírez, 1997, p. 7).

Así, el arte de la imagen es una totalidad que muestra una particularidad, siendo ésta una idea o una perspectiva. Al contemplar un objeto artístico, el aprendiz y el espectador empiezan a formar parte de un proceso de visión e intelección del mundo iniciado por la mano del artista. Ver la obra es pensar en lo que significa y compartir sus matices, fragmentarlos en la intuición cognitiva, es reconocer un dato e interiorizarlo en una dinámica de conocimiento instantánea pero certera. La apelación a las imágenes es lo que hace posible que otros escenarios diferentes al aula y a la escuela puedan convertirse en lugares de aprendizaje. Las galerías, las plazoletas, los muros pintados de las avenidas y los museos, son espacios que multiplican este aprendizaje de modo secreto e infinito. La escuela asiste hoy al museo y a la galería en busca de saber, así lo atestiguan algunos:

En cuanto a los escolares se refiere, la visita guiada, se ha convertido en la actividad educativa por excelencia. Generalmente, son realizadas por un educador y tienen como objetivo facilitar el diálogo entre la exposición y los estudiantes. El museo ayuda a los estudiantes en la comprensión de las obras como en la ampliación de conocimientos sobre determinadas temáticas. Actualmente, se busca que los educadores motiven el diálogo y la participación colectiva para establecer nexos entre el mensaje expositivo y los conocimientos previos de los visitantes (Miralles, 2016, p. 47).

Solo en una cultura abierta al cambio y a nuevas perspectivas de educación es posible encontrar al educador en una sala del museo, en una avenida, o frente a un muro adornado de grafitis, y aunque dicha práctica cuente con un historial relevante, solamente hasta hoy la vivencia del arte pictórico en esos lugares es un fenómeno interdisciplinar. Desde esa 
Algunas aproximaciones a la relación entre el arte pictórico

Artículo

y la práctica educativa: descripción de un sentimiento pedagógico

experiencia particular de la obra artística el docente puede abarcar y desarrollar otros contenidos curriculares de materias diferentes a la suya. Aquí se puede hallar el tercer uso del arte pictórico como recurso pedagógico: es un espacio real que favorece el conocimiento y la intuición y pone al espectador frente a la diversidad del saber y del acontecer. La imagen es una invitación franca a pensar en otros mundos. De alguna manera, es una respuesta que se hace pregunta y una pregunta que se hace respuesta. La interrogación y la emoción, como componentes del proceso de interpretación de la obra de arte, son tareas que favorecen la cognición. En los lienzos se concentra y revierte este proceso sensible-racional que favorece el conocimiento, el recuerdo y la intuición. Es una síntesis que enlaza algunos componentes:

En el arte pictórico estos dos elementos, percepción y sentimiento, el primero ligado con los sentidos, con el aprendizaje, con la parte lógica de la persona y el segundo, atado a la sensibilidad y la intuición, conforman un hecho integrador y complementario que no se ha tenido en cuenta en el sistema educativo a través de la historia (Ruiz, 2007. p. 17).

Así que el aula escolar abre sus ventanas al mundo del aprendizaje si facilita y estimula el hallazgo del arte pictórico como una dimensión que sintetiza estos elementos en la dinámica de la enseñanza.

Hasta aquí se entiende que el arte pictórico es una finalidad y un objeto de conocimiento que se presenta como dato y posibilidad para el que aprende. Pero el arte va más allá: su implementación puede ser un modo de abordaje de diferentes contenidos. Así como el currículo de la escuela es una manera de leer e interpretar el mundo y la cultura (traerlos a la mente de los estudiantes), el arte pictórico lleva otro tipo de saberes y experiencias a la mente de los interesados; se hace a la vez competencia y producto del trabajo académico y por eso,

el proceso estético-educativo incluye una serie de habilidades adquiridas por el ser humano en el tiempo, es decir, la exploración en lo grupal a lo individual como elemento representativo, tal como la invención, la creación, la imaginación y la sensación. Esto es un reflejo claro de que el ver implica pensar, no sólo como estética y metáfora de los procesos creativos, sino como un objeto en una obra de arte (Novoa, 2003. p. 2)

Un ejemplo de esto puede visualizarse con aportes de la poesía y algunas experiencias pedagógicas en los museos, como se señalaba. En el ámbito de la creación poética,

ESCENA. Revista de las artes, 2021, Vol. 80, Núm. 2 (enero-junio), pp. 56-80 
la visión de la obra artística invita al autor a una reflexión que de alguna manera insinúa una meditación metafísica. Pero este proceso no es sólo de contemplación sino de interpretación, por eso, el acercamiento al arte pictórico es creación particular. La poesía que resulta de la fascinación por la pintura es profunda en la medida en que hace que el objeto artístico diga algo más y más intenso. En el famoso poema de Joaquín Giannuzzi, "Los pies en el Cristo de Grünewald", puede apreciarse el caso de este aprendizaje y de esta meditación. La escena puede representar al poeta en silencio, frente al cuadro de Grünewald, mirando los detalles de la pintura y estableciendo un vínculo con lo que la obra de arte quiere significar y comunicar:

Imagen 1. Detalle de La crucifixión de Cristo de Grünewald

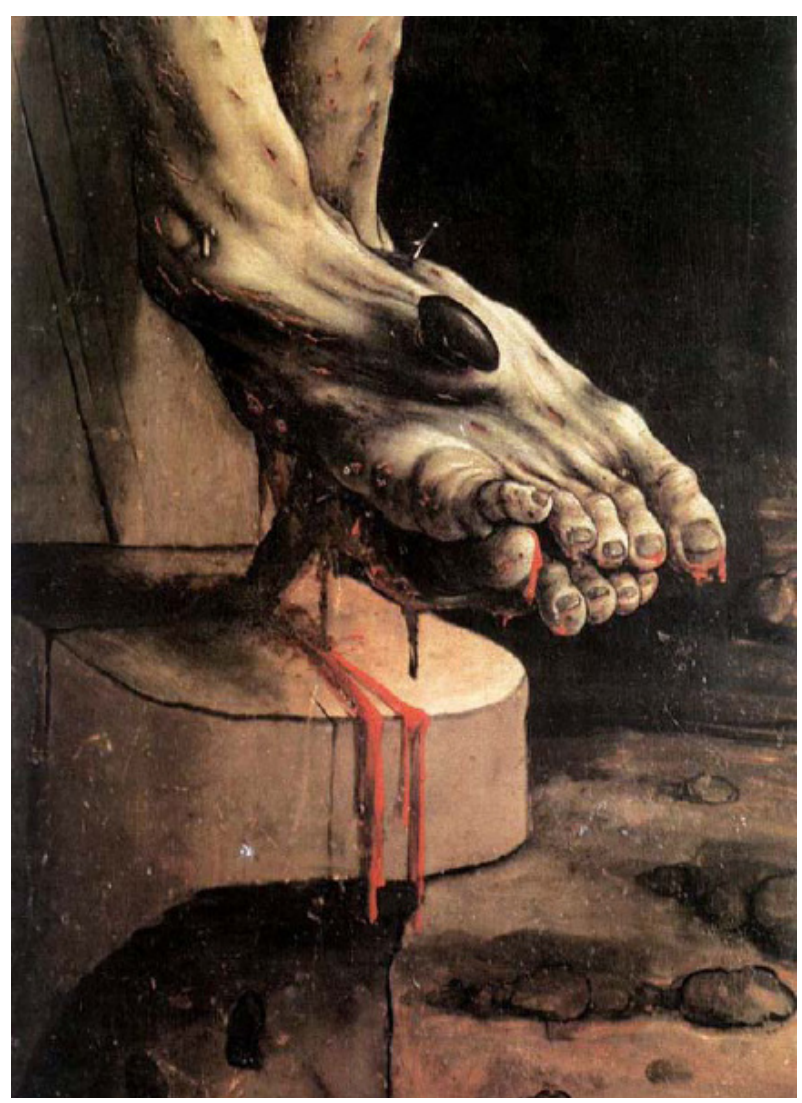

Fuente: Elso Torralba (s.f.).
El nervio expuesto y condenado / Hace de todo sufrimiento un principio general. / Todavía es la hora del descenso / Y toda carne debe seguir aquí, resolverse / En una pesada concentración. / El tono de la pintura / Define el desagüe de la masa desesperada. / La anatomía es gruesa, de tierra sangradalY allí donde los dedos se enciman / -los caminos de este mundo están bloqueados- / el límite de la torsión es crítico. / La promesa de toda resurrección tiende a la oscuridad / En las fibras musculares, giradas / Sobre sí mismas. Cada detalle / Aguarda un orgánico estallido, / Pero el conjunto fija el tormento hasta el fin de los tiempos. / Un solo clavo y se acaba la vieja danza (Giannuzzi, 2015, p. 3).

Poema que hace evocar en el lector una dolorosa imagen cuya visión termina por admitir. Desprendiéndose de lo anterior, el arte pictórico supone otra función de índole pedagógica: la de hacer visible, poética- 
Algunas aproximaciones a la relación entre el arte pictórico

Artículo

y la práctica educativa: descripción de un sentimiento pedagógico

mente, el ámbito de valores como la espiritualidad, la belleza y la compasión. Si se pudiesen incluir la pintura y la imagen como procedimientos, objetos y finalidades del currículo en las prácticas pedagógicas, podrían renovarse los tratamientos de materias como ética, historia, religión, literatura y otros contenidos curriculares de variada naturaleza. Lo sublime, en términos kantianos, hace parte de todos ellos.

Algunos de los objetos constitutivos más valiosos de la existencia humana pueden hallar expresión efectiva en las obras de arte. Los valores culturales más destacados de la civilización occidental pueden encontrarse en la visión de la obra de arte, de ahí que el lenguaje que involucra imágenes pueda desarrollar algunas facetas de la cognición según la máxima rousseauniana de que todo lo que toca las puertas del corazón abre las puertas de la mente. El arte pictórico, como cualquier arte, se dirige a los sentidos, pero en algún momento toca la razón y promueve en ella la asimilación de referentes y caracteres espirituales.

\section{El arte pictórico y otros espacios y fines educativos}

Además de los usos y ámbitos destacados en el anterior apartado, el arte pictórico se ha empleado en otros espacios de la cultura contemporánea que trascienden la esfera de la institución educativa aunque sigan siendo fenómenos de creatividad y formación personal. La pintura y la imagen, acompañadas de la música y la literatura, llegan actualmente al aula hospitalaria, a los barrios marginales, a los procesos de construcción de la paz, a la educación no formal y un prolongado etcétera. En estos espacios el arte pictórico resalta por sus notables efectos en las capacidades cognitivas y afectivas de quienes lo vivencian.

En el estudio realizado por Reyes, Escallón y Fajardo-Velasco, del año 2018, se les atribuyen a las artes la posibilidad de mediar en la transformación de procesos sociales y educativos que a su vez repercuten en la creación de nuevas redes neuronales que potencializan el aprendizaje de aspectos cognitivos y sociales (citado por Cuadros, Ruiz, \& Lewis, 2019, p. 87).

Un ejemplo de este fenómeno se encuentra asociado al trabajo que un grupo de educadores y psicólogos realizan con niños diagnosticados con trastorno de déficit de atención, TDAH, y en el cual la anterior concepción de las artes es el eje transversal de la terapia con los pacientes. Aquí el arte es considerado en su generalidad y vinculado a la fruición, el carácter que la tradición enlaza específicamente con la música, la literatura y la pintura. El empleo pedagógico y lúdico de las tres está orientado hacia la recuperación de funciones

ESCENA. Revista de las artes, 2021, Vol. 80, Núm. 2 (enero-junio), pp. 56-80 
ejecutivas, siendo preeminente el empleo de la música. La armonía de los sonidos equivale a la armonía de los motivos en la creación de los productos artísticos. Esta equivalencia es terapéutica y ayuda a los niños a mejorar su condición y a reaprender algunas de las funciones básicas en el proceso de tratamiento del trastorno médico. Así podría resumirse esta aseveración:

En el trastorno de déficit de atención, TDAH, las FE [funciones ejecutivas] más afectadas son aquellas capacidades cognitivas implicadas en la resolución de situaciones imprevistas o cambiantes y que pueden agruparse en una serie de componentes: las capacidades necesarias para formular metas, facultades para la planificación de los procesos y las estrategias para lograr los objetivos, y las habilidades para la ejecución de los planes, convirtiéndose en un eje fundamental para el desarrollo (Ruiz Gómez, Cuadros \& Hard slwis@, 2018, p. 86).

Estas funciones son parte vital en los procesos de desarrollo de los seres humanos y están vinculadas con el proceso cognitivo que a su vez es importante para la calidad de vida de todas las personas; por ello, intervenir en su rehabilitación es imperativo en los niños que padecen tal enfermedad. Las terapias que se emplean en su erradicación hacen del arte, la literatura y la música, no sólo objetos de conocimiento sino recursos que bien podrían ser medicinales o coadyuvantes de referencia pedagógica.

El aula hospitalaria se está transformado también en un espacio más amplio de formación gracias, justamente, a la implementación de actividades provenientes del canon del arte pictórico. Las experiencias educativas en dichos contextos nacen por lo regular en los procesos de formación universitaria del personal a cargo. Los elementos que del arte pictórico llegan hasta estos contextos son de tipo práctico: elaboración de dibujos, uso de témperas, arcillas y plastilinas, creación de imágenes, talleres de apreciación artística y otros. Estos componentes y actividades se disponen para el aprendizaje de los niños en las aulas hospitalarias y los procesos y resultados de los mismos siempre devienen en una satisfacción íntima para los aprendices-pacientes y los tutores. El arte pictórico en el hospital adquiere así una función coadyuvante y socializadora: acorta las distancias entre los diferentes actores del contexto y estimula la vivencia de un clima distinto en el padecimiento de la enfermedad.

En las calles y los barrios, el arte pictórico ha sido siempre la cristalización de las emociones de las mayorías y ha asumido, a pesar de su carga ideológica, la expresión 
Algunas aproximaciones a la relación entre el arte pictórico

Artículo

y la práctica educativa: descripción de un sentimiento pedagógico

del descontento popular. Aunque el arte en las calles y los barrios se estigmatice con los apelativos de propaganda, ideología o vandalismo; el uso que de él se hace es diferente al contenido que él expresa. Existen diversos sentimientos políticos, sociales y culturales que las personas en contextos de marginalidad y explotación denuncian a través de las artes y de las imágenes artísticas. La queja se vive en la escuela, la cuadra, la familia o la comunidad, y para encauzarla, los líderes sociales apelan con frecuencia a herramientas pedagógicas de carácter ilustrativo.

Por tal razón creemos que las artes plásticas como estrategia didáctica, nos permiten recrear el escenario escolar y desarrollar dinámicas de participación espontánea, así como abordar, expresar e interpretar la realidad desde diversas posturas y sentires acerca de las concepciones y factores que conducen a la consolidación de una cultura de paz (Fajardo \& Reyes, 2018, p. 101).

Este fenómeno no es nuevo ni gratuito, en la práctica es también la forma en que los marginados muestran a los demás el núcleo de su denuncia. La pancarta, el afiche, la imagen y las figuras, no constituyen una sátira sino un mecanismo de enseñanza, quizás el más resumido y auténtico, que presta su voz a quienes tradicionalmente no pueden hacer uso de ella. La denuncia con recursos artísticos no es rara en las naciones en desarrollo y mucho más en las culturas en las que la educación y la vida familiar se encuentran bajo el peso de la sofocación económica y las formas dominantes. Esto es todavía más común en contextos socioculturales en donde la práctica educativa se resiste a la transformación y se convierte, de manera permanente, en expresión de la dominación. La tiranía que impulsa estas rebeliones tiene algunos puntos de fuga perfectamente delimitados en las comunidades urbanas:

Por medio de la educación y su currículo, se inculca un tipo de hegemonía cultural, definida por los mismos grupos dominantes, a partir de ejes temáticos, modelos de comportamiento y acciones propias de las escuelas que defienden y reproducen un tipo de estructura social y a la vez reafirman la desigualdad (Ávila, 2005, citado por Fajardo y Reyes, 2018, p.103).

Tanto en la escuela como en la sociedad hay formas evidentes y a veces engañosas de replicar prácticas de opresión que sólo pueden ser atenuadas a través de mecanismos que tienen que ver con el arte. En estos fenómenos llama la atención que en la mayoría de tales patrones ocultos, las materias y los contenidos que tendrían que ver con la libertad,

ESCENA. Revista de las artes, 2021, Vol. 80, Núm. 2 (enero-junio), pp. 56-80 
la emancipación, la creatividad y el disenso son extirpados por completo para sostener y desarrollar las habituales estructuras teóricas que justifican el orden social imperante. Los currículos cerrados muchas veces son tales porque la visión estética, las artes, la filosofía y otras ramas del saber y del hacer, han sido descalificadas previamente de sus linderos. En respuesta a este acontecimiento, muchos intelectuales, maestros y líderes sociales, reivindican las artes como espacios que contribuyen al cambio político y a la liberación individual y social. La transformación que pueden operar el arte y la estética conduce a una nueva visión de la vida y a una valoración distinta de los cambios sociales,

Por lo tanto, el arte se opone a lo real, apunta a otras realidades, completa la vida y amplía sus posibilidades, revela las contradicciones, surge de la insatisfacción en el vislumbre de otras alternativas y ayuda a la toma de conciencia de lo que realmente es sustantivo de la vida... en la experiencia del arte se involucran todas las funciones psíquicas, trabajando de manera semiótica, usando herramientas que posibilitan emerger significados, en este recorrido, emparentado con lo sorprendente y sugerente, la conciencia ha de sentirse plena de disfrute (Barco, 2006, pp. 75-76).

El fenómeno no sólo tiene un antecedente y una manifestación populares, también tiene una tradición en la historia de la pintura. En la serie Los desastres de la guerra, del pintor español Francisco de Goya, se encuentra una censura de las fatalidades de la guerra. El maestro, a través de la representación de figuras deformadas, hace una denuncia de las atrocidades derivadas de los conflictos. Para su mente creativa, la imagen es el vehículo adecuado para comunicar la reprobación y la indignación frente a la barbarie.

En la estampa introductoria del álbum, que tiene el significativo título, "Tristes presentimientos de lo que ha de acontecer”, Goya utiliza una sencilla composición pictórica explicativa formada por una figura de rodillas y en actitud suplicante para mostrar la soledad e indefensión del ser humano relacionada con la realidad de la guerra que presentía. Esa realidad es la que crea las atroces imágenes que Goya recoge en escenas, donde el tema son los horrores de la contienda. Rompe con la concepción de lo heroico y muestra la cruda realidad de la guerra, la que sufre el pueblo, y como un reportero gráfico actual, no retrata a la persona sino el momento y la situación. Goya utiliza, lógicamente, los necesarios detalles iconográficos para presentar a los soldados franceses, a los guerrilleros españoles y a la gente del pueblo, e igualmente para expresar la dura realidad de las víctimas de la guerra (Balsalobre, 2002, pp. 20-22). 
Algunas aproximaciones a la relación entre el arte pictórico

Artículo

y la práctica educativa: descripción de un sentimiento pedagógico

Imagen 2. Yo lo vi. Grabado de Francisco de Goya

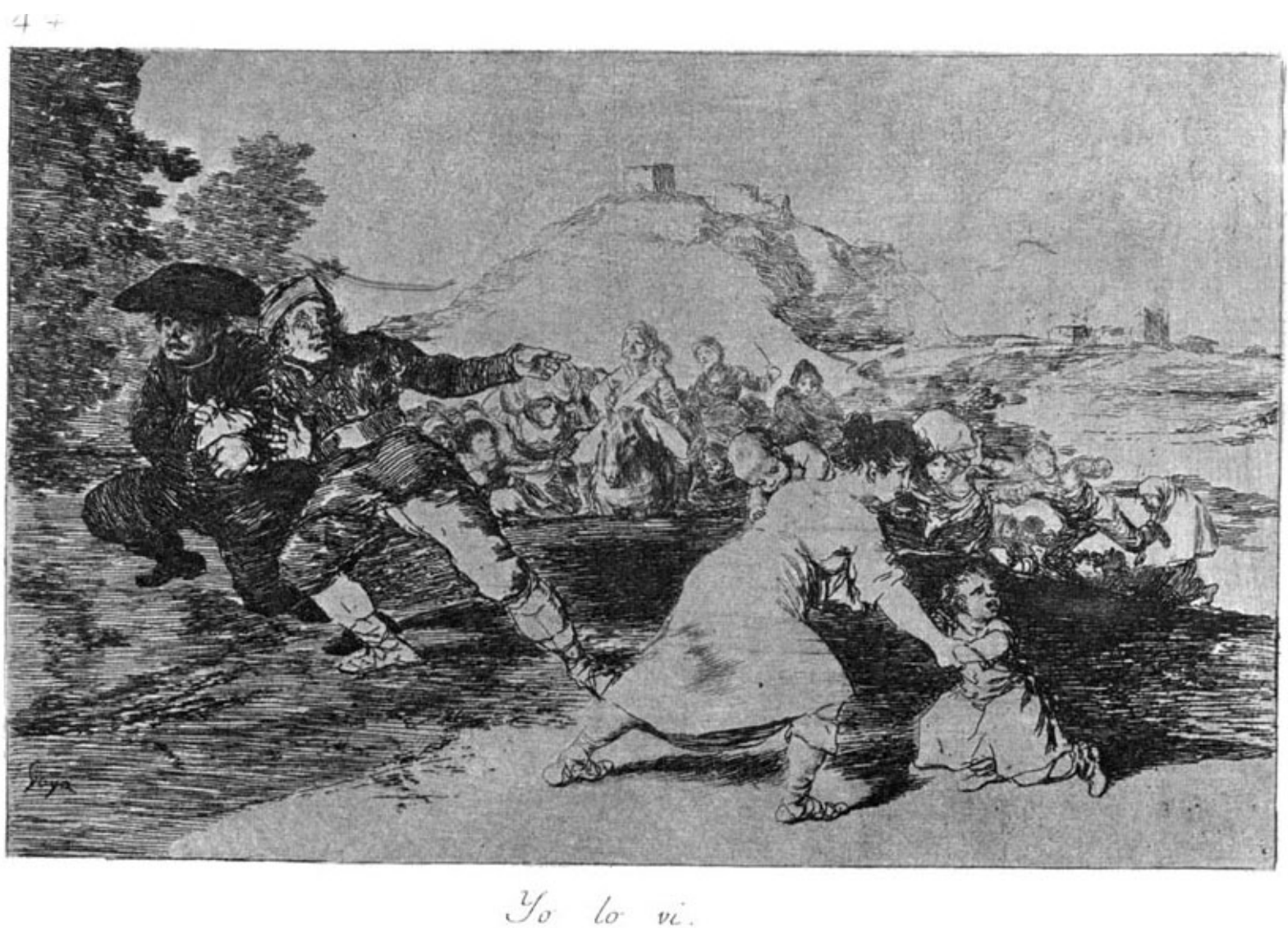

Fuente: Muro (21 de noviembre de 2006).

A través de la pintura, no solamente la del genio español, sino la de todos los artistas posteriores, modernos y contemporáneos; la reprobación de las crueldades ha sido expresada de muchas maneras y quiérase o no, de un modo que enseña y transmite la censura a la violencia cualquiera sea su origen.

Y quedaría incompleta la descripción del arte pictórico como denuncia social, sin la alusión obvia al cuadro "Guernica" de Pablo Picasso, elaborado a partir de los bombardeos alemanes a la ciudad española de Guernica en 1937. En dicha obra, los elementos que la componen se encuentran dispersos, a la manera de las figuras de Goya, en una gigantesca composición que transmite genialmente la idea del caos y del sufrimiento que ocasionó el 
bombardeo. Sorprende en el lienzo la presentación de animales heridos y agonizantes, en conjunto con figuras humanas, muertas y despedazadas. El Guernica, con su simbolismo y peculiar valor estético, se ha convertido en un ícono universal que evoca el valor y la necesidad de la paz en un mundo cada vez más violento. Es este carácter el que precisamente lo ha convertido en piedra angular de procesos de sensibilización social y de enseñanza, como en el caso de las obras de Ana Alonso, en la colección Pizca de sal, quien, en sus guías de lectura, lo emplea como insumo para desarrollar procesos de comprensión en los niños:

Antes de comenzar a leer Dentro del Guernica, podemos mostrar a los niños y las niñas de la clase una reproducción del Guernica de Picasso. Dejaremos que ellos comenten la pintura, lo que creen que representa y lo que sienten cuando la miran, resaltando que cuando abordamos una obra de arte no hay interpretaciones correctas e incorrectas y todas las miradas pueden aportar algo. Al final de la sesión, explicaremos brevemente a los alumnos la relación del Guernica con la guerra civil española, y el

Imagen 3. Guernica de Pablo Picasso

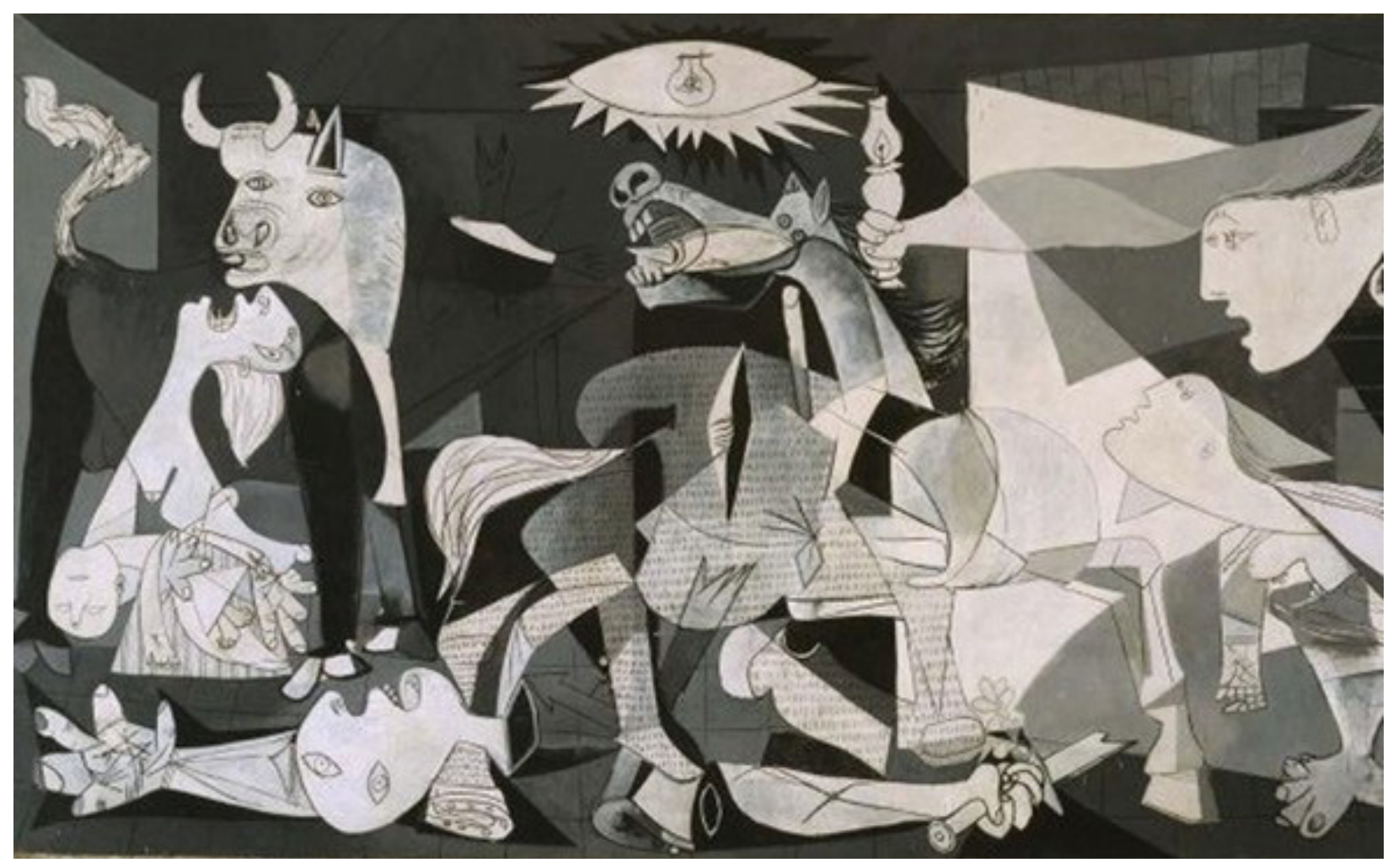

Fuente: Gutiérrez (7 de abril de 2017)

ESCENA. Revista de las artes, 2021, Vol. 80, Núm. 2 (enero-junio), pp.56-80 
Algunas aproximaciones a la relación entre el arte pictórico

Artículo

y la práctica educativa: descripción de un sentimiento pedagógico

motivo por el que podría considerarse una obra de arte pacifista (Alonso, 2018, p. 9).

Este ejemplo es una demostración de que el carácter pedagógico del arte pictórico puede caber en la escuela y la cultura favoreciendo miradas interdisciplinares. Aquí convergen, como puede advertirse, la dinámica social y cultural del arte pictórico con su uso como herramienta didáctica. Es un caso especial por cuanto la idea original del autor del cuadro, que no era sólo la denuncia sino la invitación a la reflexión, se transforma en una intención y una acción pedagógicas. Utilizar el cuadro para invitar a los niños a hacer sus primeros avances en la escritura y en la comunicación es una característica de la ductilidad del arte pictórico y una muestra de su poder de divulgación y expresión. En el arte que muestra o discute alguna realidad el aprendizaje de quien observa se traduce en maneras diversas de asumir esa misma realidad. Se aprende a mirar de nuevo y a deliberar sobre lo mirado. Es por eso que el acto de mirar converge con el de pensar, como lo señala Eisner:

Una función cognitiva de las artes es ayudarnos a aprender a observar el mundo. Un paisaje de Monet o una fotografía de Paul Strand hacen posible una nueva manera de ver. Los brillantes colores de Monet nos ofrecen una nueva manera de ver la luz. Las fotografías de Paul Strand nos ofrecen una nueva manera de experimentar la geometría de las ciudades industriales. El arte nos ofrece las condiciones para que despertemos al mundo que nos rodea. En este sentido, las artes nos ofrecen una manera de conocer (Eisner, 2004, p. 27).

Por consiguiente, en las obras de Goya y de Picasso, en las que la denuncia de la guerra y de sus atrocidades es el tema original, la mente del espectador no sólo reacciona asintiendo o negando, sino también disfrutando, es decir, apreciando. Los conflictos armados como las disputas territoriales, la violencia urbana y las diferencias ideológicas entre grupos extremistas pueden ser abordados y reproducidos por el arte pictórico, y la dimensión educativa de tal acontecimiento puede empezar por la reflexión y la aprehensión de sus distintos motivos.

\section{A manera de síntesis}

Para concluir esta serie de reflexiones, es necesario resaltar los aspectos y las implicaciones que las preguntas iniciales exigían en el desarrollo del artículo. Dichas cuestiones comenzaban por la necesidad de establecer la naturaleza del arte pictórico, su relación con la obra de arte y los usos y espacios que dicho arte podría ocupar en la formación

ESCENA. Revista de las artes, 2021, Vol. 80, Núm. 2 (enero-junio), pp. 56-80 
académica de los vivientes en los ámbitos propicios para ello.

Con respecto a estas primeras inquietudes puede verse que el arte pictórico es un proceso y un producto relacionado con los mecanismos que permiten construir imágenes valoradas como artísticas. El arte pictórico es un fenómeno real, asociado a los tiempos y a las costumbres de las civilizaciones humanas a lo largo de la historia. Es una manifestación del espíritu humano que ha desempeñado diferentes papeles en cada etapa cronológica: ha sido motivo de comunicación, de expresión, de costumbres, de enseñanza y de creación de identidades culturales. Su fecundidad es vasta por cuanto sus principios y realizaciones han permeado otras artes como la poesía, la música y la arquitectura.

En referencia a sus espacios como fenómeno educativo, se ha visto que su desarrollo es geográfico por cuanto en diversas partes del globo, su génesis y su vivencia son diferentes, peculiares, propias de cada nación y de cada segmento de la cultura. En Colombia, lentamente, empieza a formar parte de propuestas educativas vinculadas a instituciones académicas, museos, barrios y proyectos sociales. En dichos ámbitos, el arte pictórico ha sido empleado como mecanismo de aprendizaje, objeto de estudio y forma de expresión de las minorías en contra de los conflictos y las presiones económicas y sociales vividas por la población. Y también se ha visto que estos fenómenos son productos, igualmente, de coyunturas históricas y culturales, lo que ha afectado también su naturaleza y percepción. El arte pictórico es una circunstancia que crece alimentada del suelo que lo nutre.

En cuanto a la dimensión del arte pictórico como agente educativo, está claro que su vivencia, valoración y enseñanza son de naturaleza estética y cognitiva. En la visión e interpretación de la pintura y las imágenes, el ser humano de todas las épocas ha encontrado perspectivas y sentidos de la naturaleza y la imaginación que le han permitido experimentar gozo, admiración y entendimiento; la esfera de los productos del arte como maestro es infinita.

El arte pictórico ha dejado paulatinamente los espacios restringidos de las culturas de élite y ha podido gestarse, vivirse y reproducirse en contextos variados llevando a todos ellos una consideración particular de la realidad. Poco a poco, la imagen, el dibujo, la figura y demás representaciones pictóricas, oscilando entre lo popular y lo clásico, lo convencional y lo novedoso; han acortado las distancias entre el público y los grandes creadores. La escuela misma ha sido testigo y partícipe de este proceso, involucrando herramientas, elementos, objetos y creaciones artísticas en la ejecución de alguna parte de sus currículos.

Frente al discurso teórico, habitual modo de transmitir los conocimientos, el arte pic- 
Algunas aproximaciones a la relación entre el arte pictórico

Artículo

y la práctica educativa: descripción de un sentimiento pedagógico

tórico ha representado un desafío que obliga constantemente a las instituciones a revalidar sus modos didácticos y sus esquemas operativos. Entre más frecuente sea el arte como recurso y objeto académico, mayor necesidad de transformación de la práctica educativa podrá adivinarse.

El arte pictórico como modo y fin de prácticas educativas ha encontrado espacios de desarrollo y divulgación que traspasan las fronteras en los países de habla hispana y que pueden ser referentes especiales en una valoración global de sus posibilidades por fuera del aula. En la barriada mexicana, las representaciones de la Virgen de Guadalupe, por ejemplo, son significativas en tanto a su alrededor se une la comunidad para el rezo o la recordación de difuntos. La obra los grafiteros en las ciudades de Bogotá y Medellín, en Colombia, son también mensajes que reflejan un arte y un sentir representativos de la cultura. En diversas manifestaciones de protesta, en Lima, Quito, Guatemala, Bogotá y otras urbes latinoamericanas, las pancartas con temas pictóricos; indigenistas, entre otros, son corrientes y representan un principio de lucha y de reivindicación social.

La publicidad es también otro ámbito en que el arte pictórico encuentra expresión y originalidad: múltiples eventos culturales, académicos, y también productos como libros, cuadernos, agendas, afiches y demás, todos referidos a la academia, usan figuras artísticas para embellecer el contenido de los mismos. Lo mismo ocurre en el séptimo arte. Las imágenes de la cinematografía se esmeran por parecer delicadas, transmitiendo rasgos esenciales de la obra artística.

Los aprendizajes suscitados por el arte pictórico han tenido siempre como medio y fin de su realización, la interioridad humana. El arte es una experiencia que alienta la espiritualidad, la introspección, la maravillosa tarea de asombrarse frente a infinidad de objetos. La memoria y la conciencia pueden ser aulas de aprendizaje para cada ser humano gracias al arte pictórico y su faceta creadora.

Son igualmente aprovechables, para la escuela, como para la cultura y la educación, las relaciones específicas que el arte pictórico mantiene con la literatura, especialmente la poesía y la narrativa. Poetas y narradores han aprendido muchas cosas de la tradición pictórica occidental, entre otras, a mirar de nuevo sobre ellos mismos y sus obras, sobre sus motivos y palabras. En algún punto, la literatura se ha nutrido de la pintura, así como la música y el teatro. Se espera que la educación pueda hacer otro tanto.

ESCENA. Revista de las artes, 2021, Vol. 80, Núm. 2 (enero-junio), pp. 56-80 


\section{Referencias}

Abad, J. (2004). Educación artística, Cultura y Ciudadanía. Colombia: Ed. Santillana.

Alonso, A. (2018). Dentro del Guernica (Colección: Pizca de Sal). Madrid: Ed. Anaya.

Balsalobre García, J. M. (2002). Una Mirada a Goya: Los desastres de la Guerra. Revista Espacio, Tiempo y Forma. Serie V, Historia Contemporánea, (15), 13-23. Recuperado de http://revistas.uned.es/index.php/ETFV/article/view/3078/2938

Barco, J. M. (2006). Vygotsky: las emociones y el arte. Praxis Pedagógica, 6(7), 70-77. Recuperado de https://revistas.uniminuto.edu/index.php/praxis/article/view/934

Bedoya, H.G. (2009). Una imagen vale más que mil palabras ¿ver o mirar? Revista, Zona Próxima, 10, 197-215.

Carrillo, C. J. (2017). El arte pictórico en relación con la historia [blog]. Recuperado de: https:// oldcivilizations.wordpress.com/2012/09/28/el-arte-pictorico-y-su-relacion-con-la-historia-de-la-humanidad/

Comenio, Juan A. (2013). Didáctica Magna. México D.F. México. Ed. Porrúa.

Cuadros, J.; Lewis, S. \& Ruiz, F. (2019). Neuroarte: un programa para el fortalecimiento de las funciones ejecutoras en niños con TDAH. Inclusión y Desarrollo, 6. Recuperado de http//revistasuniminuto.edu/

Eisner, E. (2004). El arte y la creación de la mente: El papel de las artes visuales en la transformación de la conciencia. Barcelona, España: Editorial Paidós.

Elso Torralba, S. (s.f.). Detalle de La crucifixión de Cristo [Óleo sobre tabla de Grünewald]. Recuperado de http://poesia-pintura.blogspot.com/2012/04/los-pies-en-el-cristo-degrunewald-de.html

Fajardo, A., (2012). Estrategias para la enseñanza/aprendizaje del patrimonio histórico y cultural. El caso del Museo Colonial. Museo Iglesia de Santa Clara. Praxis Pedagógica, 12(13), 104-123. Recuperado de https://revistas.uniminuto.edu/index.php/praxis/ article/view/496

Fajardo, J. \& Reyes, M. (2018). Creando y sintiendo: prácticas artísticas para la construcción de una cultura de paz. Inclusión y Desarrollo, 5(2), 101-124. DOI: https://doi. org/10.26620/uniminuto.inclusión.5.2.2018.101-124 
Algunas aproximaciones a la relación entre el arte pictórico

Artículo

y la práctica educativa: descripción de un sentimiento pedagógico

Gutiérrez, I. (7 de abril de 2017). Guernica [óleo sobre lienzo de Pablo Picasso]. Recuperado de https://www.cronista.com/negocios/La-historia-del-guernica-de-Picasso-20170407-0001.html

Hegel, G.H.W. [1842] (2002). Lecciones de Estética. México D.F.: Ed. Coyoacán.

Juarroz, R. (1958). Poesía Vertical. Antología Poética. Recuperado de: http://www.paginadepoesia.com.ar/escritos_pdf/juarroz_poesiavertical.pdf

Lowenfeld, V. \& Lambert, W. (1975). Desarrollo de la capacidad creadora. Buenos Aires, Argentina: Ed. Kapelusz.

Miralles Jara, N. (2016). Educación artística en museos: sinergia entre aula y museo. Actualidad y desafíos en la construcción de una alianza. Praxis Pedagógica, 16(19), 43-59. Recuperado de https://revistas.uniminuto.edu/index.php/praxis/article/view/1375

Muro, J. (21 de noviembre de 2006). Yo lo vi [grabado de Francisco de Goya]. Recuperado de https://juanmuro52.files.wordpress.com/2010/11/yo-lo-vi.jpg

Novoa Gordillo, A. (2003). Los lenguajes de Expresión Artística: un camino para comprender la educación del Arte. El Aleph, 11, 4-8.

Ramírez Aissa, C. (1997). Interpretación de la obra de Arte. Bogotá: Ed. USTA.

Read, H. (2013). Al diablo con la Cultura. Argentina: Ed. Utopía Libertaria.

Ross, N. (2004). El lenguaje artístico, la educación y la creación.Revista Iberoamericana De Educación, 35(1), 1-8. DOI: https://doi.org/10.35362/rie3512901

Rousseau, J. J. (1993). Emilio, o de la Educación. México: Ed. Porrúa.

Ruiz Gómez, F.; Cuadros, J. \& Hard slwis@, S. (2018). NeuroArte un programa de fortalecimiento de las funciones ejecutivas en niños con TDAH. Inclusión Y Desarrollo, 6(1), 8392. DOI: https://doi.org/10.26620/uniminuto.inclusion.6.1.2019.83-9

Ruiz Mejía, A. (2007). El arte en la educación según Herbert Read. El Aleph, 4, 3-9.

ESCENA. Revista de las artes, 2021, Vol. 80, Núm. 2 (enero-junio), pp. 56-80 